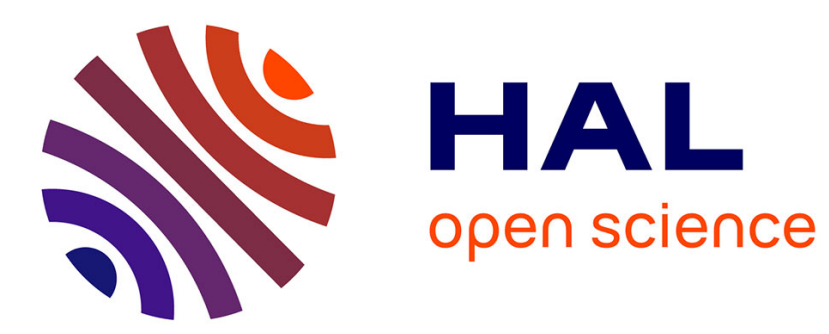

\title{
Growth kinetics of copper thin films in different MOCVD systems
}

\author{
T. Gerfin, M. Becht, K.-H. Dahmen
}

\section{To cite this version:}

T. Gerfin, M. Becht, K.-H. Dahmen. Growth kinetics of copper thin films in different MOCVD systems. Journal de Physique IV Proceedings, 1993, 03 (C3), pp.C3-345-C3-352. 10.1051/jp4:1993347 . jpa00251404

\section{HAL Id: jpa-00251404 https://hal.science/jpa-00251404}

Submitted on 1 Jan 1993

HAL is a multi-disciplinary open access archive for the deposit and dissemination of scientific research documents, whether they are published or not. The documents may come from teaching and research institutions in France or abroad, or from public or private research centers.
L'archive ouverte pluridisciplinaire HAL, est destinée au dépôt et à la diffusion de documents scientifiques de niveau recherche, publiés ou non, émanant des établissements d'enseignement et de recherche français ou étrangers, des laboratoires publics ou privés. 


\title{
Growth kinetics of copper thin films in different MOCVD systems
}

\author{
T. GERFIN, M. BECHT and K.-H. DAHMEN
}

Laboratorium für Anorganische Chemie, ETH Zürich, Universitätsstrasse 6, 8092 Zürich, Switzerland

\begin{abstract}
Thin copper films were grown in two different MOCVD systems using bis(2,2,6,6-tetramethyl-3,5-heptadionato)-copper, $\left[\mathrm{Cu}(\text { thd })_{2}\right]$, as precursor. The experiments were carried out in a horizontal hot-wall quartz reactor and a vertical coldwall apparatus of stainless steel. The thicknesses of the films were measured by profilometry, the absorption coefficients $k$ at a wavelength of $1300 \mathrm{~nm}$ by ellipsometry and the electrical sheet resistances by four-probe measurements. The growth kinetics, which depends on the partial pressure of the precursor, on the reaction gas type and on the substrate temperature, will be discussed. A mechanism will be given for the MOCVD process in the horizontal system.
\end{abstract}

\section{Introduction}

Copper is a very promising material for metallization in ultra large scale integrated (ULSI) technology ${ }^{[1]}$ In the last two years, there have been many MOCVD investigations using copper(I) or copper(II) precursors, since this growth technique allows selective growth of metallic copper. ${ }^{[2]}$ Although $\mathrm{Cu}(\mathrm{thd})_{2}$ is widely used in the preparation of high $\mathrm{T}_{\mathrm{c}}$ superconducting films, there are only few reports about metallic copper films prepared from this compound. ${ }^{[3-6]}$

Here, we report growth experiments of copper films carried out in two different MOCVD systems using $\mathrm{Cu}(\text { thd })_{2}$ as precursor.

\section{Experimental Part}

The horizontal hot-wall quartz reactor (HR) used was described earlier. ${ }^{[7]}$ Figure 1 shows a schematic picture of the vertical cold-wall apparatus (VR) in which the substrate is heated resistively. The nozzle of this system had a diameter of $20 \mathrm{~mm}$ and a distance of $5 \mathrm{~mm}$ to the 
Figure 1: Schematic Representation of the Vertical MOCVD System (VR) (TC= Thermocouple)

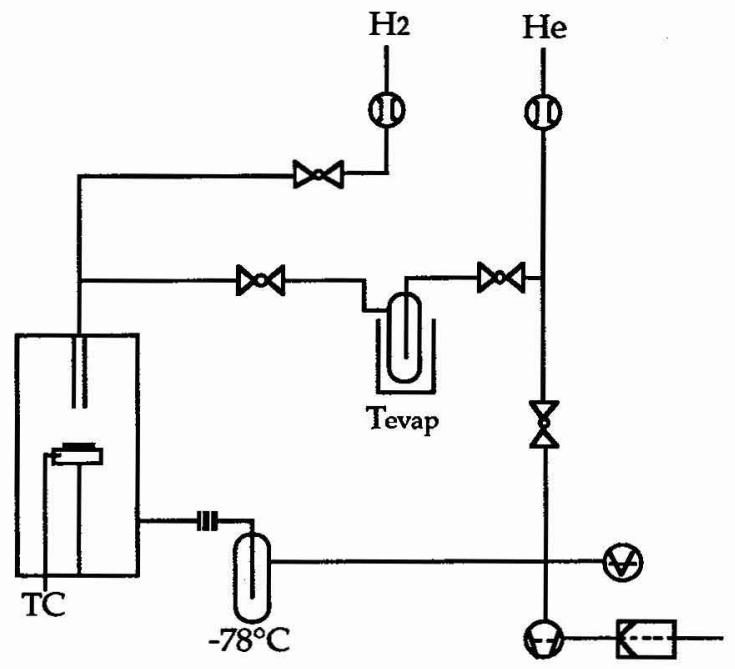

susceptor whose diameter was $31 \mathrm{~mm}$. The experimental parameters used are listed in Table I. The evaporation rate was determined by weight loss of the ceramic boat in the HR system. However, no similar values could be measured in the VR system because of a different evaporation chamber. Comparison of the two systems can only be made on the basis of the evaporation temperatures. The films were investigated by profilometry, ellipsometry $(\lambda=$ $1300 \mathrm{~nm}), \mathrm{X}$-ray diffraction and four-probe resistivity measurements.

Table I: Experimental Conditions of the Two Different MOCVD Systems

\begin{tabular}{c|c|c}
\hline & HR & VR \\
\hline substrate & quartz & quartz \\
carrier gas, flow & $\mathrm{He}, 66 \mathrm{sccm}$ & He $60 \mathrm{sccm}$ or $\mathrm{H}_{2} 30 \mathrm{sccm}$ \\
reaction gas, flow & $\mathrm{H}_{2}, 108 \mathrm{sccm}$ & $\mathrm{H}_{2}, 60 \mathrm{sccm}$ \\
pressure & $20-25 \mathrm{mbar}$ & $1-3 \mathrm{mbar}$ \\
evaporation temperature & $120-150^{\circ} \mathrm{C}$ & $105-155^{\circ} \mathrm{C}$ \\
substrate temperature & $275-550^{\circ} \mathrm{C}$ & $300-500^{\circ} \mathrm{C}$ \\
time & $5-100 \mathrm{~min}$ & $5-103 \mathrm{~min}$ \\
\hline
\end{tabular}




\section{Results and Discussion}

In Figure 2, we compare the dependence of the thicknesses of the films on the duration of the experiments using the same evaporation and substrate temperatures in both systems. There are evident differences between them. The huge growth rate of the VR system within the first ten minutes can be explained by the evaporation technique used. After this time both systems have reached a steady state and all results being reported here are measured in this region by making two experiments and correcting the data. The differences in the slope $(0.12+0.01 \AA / s$ for the VR and $0.23 \pm 0.02 \AA / s$ for the HR, respectively) may be due to different evaporation rates, different pressures or different hydrodynamics of the systems.

Figure 2: Thicknesses of the Films Measured by Profilometry in Dependence on the Duration of the Experiments $(V R-0-, H R--) .\left(T_{\text {evap }}=110^{\circ} \mathrm{C}, T_{\text {sub }}=450^{\circ} \mathrm{C}\right)$

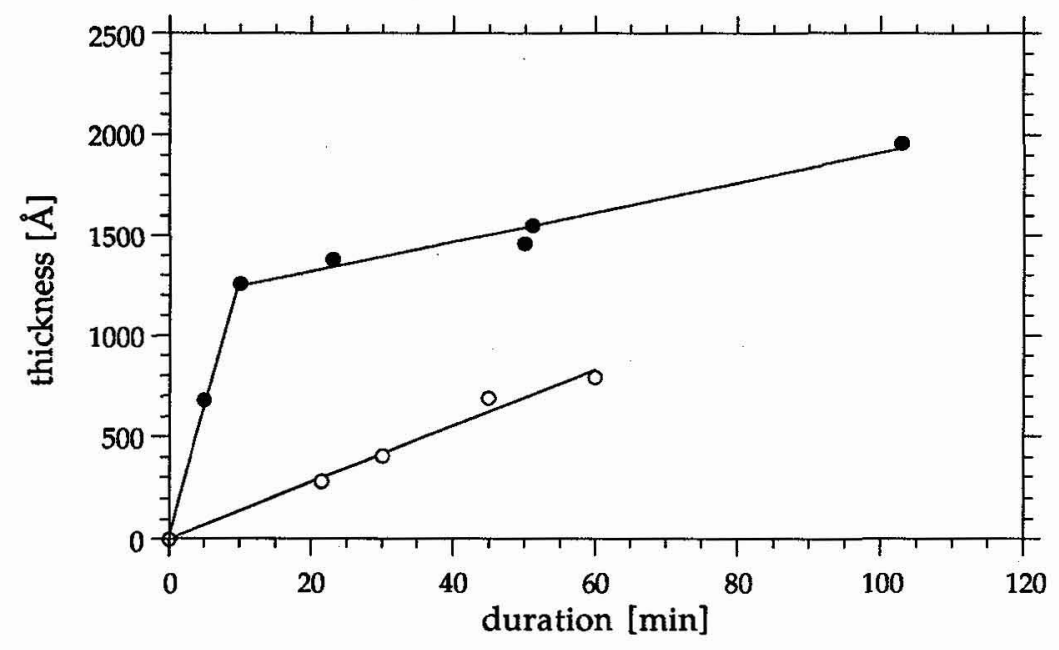

Figure 3.a shows the dependence of the growth rate on the evaporation rate in the HR system and Figure 3.b the dependence on the evaporation temperature for both systems. The curve in Fig. 3.a represents a Langmuir isotherm ${ }^{[8]}$ :

$$
G=\frac{a\left[C u(t h d)_{2}\right]^{x}}{1+b\left[C u(t h d)_{2}\right]^{x}}
$$

The exponent $x$ was fitted to a value of $1.25 \pm 0.19(a=0.26 \pm 0.03, b=0.72 \pm 0.08)$. The mechanism of a Langmuir isotherm means that the growth is determined by absorption or desorption on the surface of the substrate and not directly by mass flow of the precursor or the reaction gas hydrogen. 
There are two points in Figure 3.b which should be noted:

(1) the absolute values of the growth rates are significantly higher in the HR system,

(2) the dependence is different for the two systems, i.e., with the VR system a typical linear behavior is observed, which can be explained by mass flow control, whereas with the HR system saturation was found as described above. It can not be excluded that a similar saturation would be found in the VR system at higher growth rates.

These observations can only be stated, but there are no simple explanations for them because of intrinsically different hydrodynamics and differences in the experimental parameters.

Figure 3: Growth Rate of Copper Films at a Substrate Temperature of $450^{\circ} \mathrm{C}$. Figure 3.a Shows the Dependence of the Growth Rate on the Evaporation Rate in the HR,. Figure 3.b Shows Its Dependence on the Evaporation Temperature in Both Systems (VR -o-, HR - -)
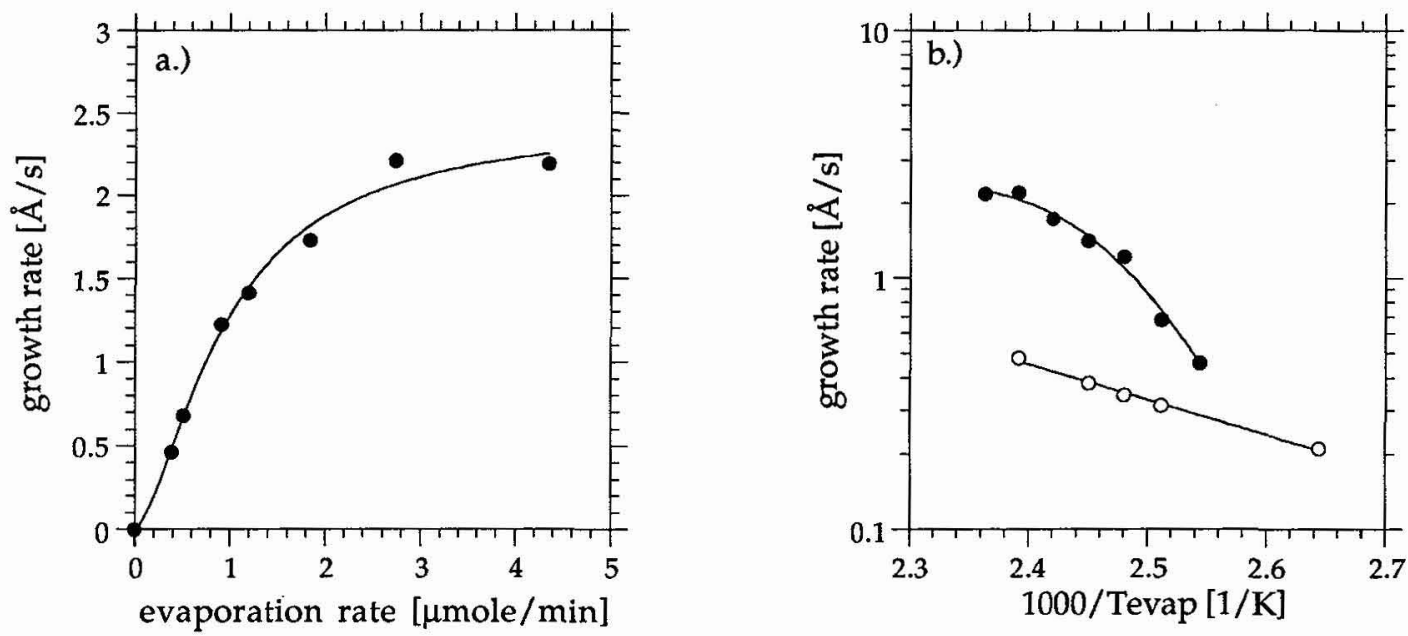

No growth is found in the HR and VR system below $270^{\circ} \mathrm{C}$ and $350^{\circ} \mathrm{C}$, respectively. In Figure 4, the growth rate is shown as a function of the substrate temperature in the $H R$ system. Two regions can be distinguished in this diagram, i.e. a strongly temperature dependent region below $290^{\circ} \mathrm{C}\left(1000 / \mathrm{T}_{\mathrm{sub}} \approx 1.7 \mathrm{~K}^{-1}\right)$ with kinetically controlled growth and a high temperature region above $290^{\circ} \mathrm{C}$ in which the surface is the limiting factor. Even though the curve fits the data quite well, significant deviations can be found at about $350^{\circ} \mathrm{C}$. Further investigations with different mass flows will give more insight into this interesting 
Figure 4: Growth Rate of Copper Films in the HR System With an Evaporation Temperature of $135^{\circ} \mathrm{C}$

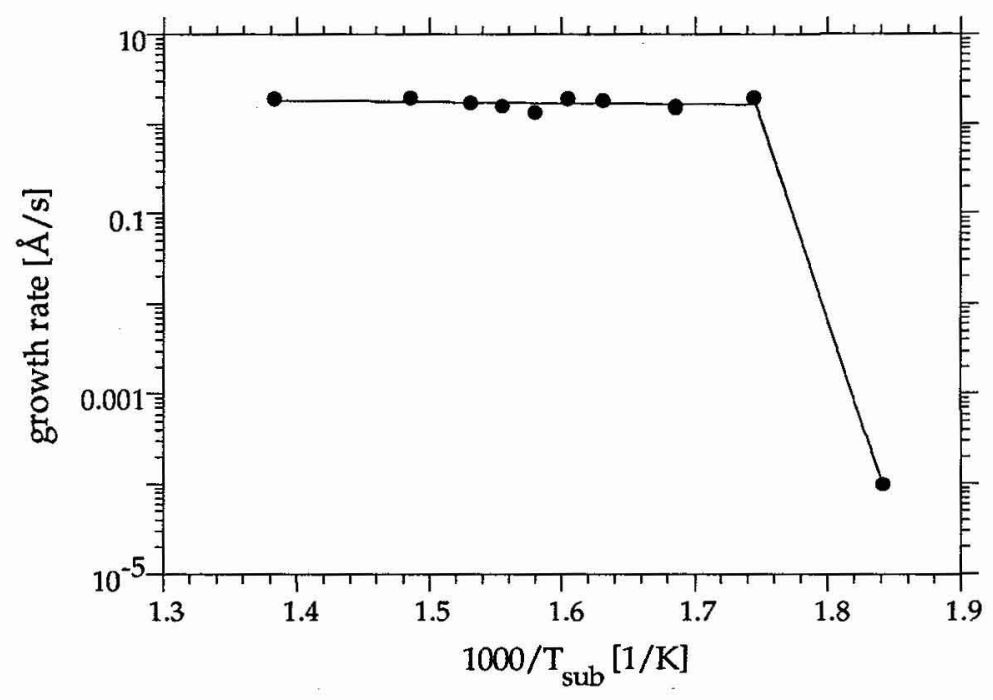

temperature behavior. Unfortunately, no comparable results are available at the moment for the VR system.

As can be seen in Figure 5.a, the behavior of the room temperature sheet resistances shows a sharp transition from insulating or semiconducting to metallic. It was not possible to determine more values in the insulating part, because those were higher than we were able to measure. The transition temperature is dependent on the evaporation rate or the growth rate, respectively. A similar effect is observed for the absorption coefficient $\mathrm{k}$ measured by ellipsometry at a wavelength of $1300 \mathrm{~nm}^{[9]}$, shown in Figure 5.b. X-ray investigations proved that the high temperature films are single phase metallic copper and the low temperature films a mixture of copper and copper(I)oxide.

P.M. Jeffries et al. ${ }^{[10]}$ investigated the growth of copper oxides and metallic copper using $[\mathrm{Cu}(\mathrm{O}-\mathrm{t}-\mathrm{Bu})]_{4}$ as precursor. They found that it is possible to grow either the metal or the oxide depending on the substrate temperature. The phase deposited seems to be controlled by the substrate temperature. Our results can be explained in the same way, as will be discussed later.

Two groups increased the growth rate with $\mathrm{Cu}(\mathrm{hfa})_{2}$ (hfa $=1,1,1,5,5,5$-hexafluoroacetylacetone) by mixing water or alcohols into the reaction gas flow. ${ }^{[11,12]}$ Our investigations of hydrogen and hydrogen/ethanol $\left(0^{\circ} \mathrm{C}\right)$ reaction gases showed no influence on the growth rate with $\mathrm{Cu}(\mathrm{dpm})_{2}$. However, Figure 6 shows the sheet resistances depending on the substrate temperature with these two gases. Using ethanol copper films are formed at all temperatures above $260^{\circ} \mathrm{C}$ (onset temperature for growth). Thus, it is possible to grow 
Figure 5: Room Temperature Sheet Resistance of Films Grown in the HR System with an Evaporation Temperature of $125^{\circ} \mathrm{C}, 130^{\circ} \mathrm{C}, 135^{\circ} \mathrm{C}$ (a.). Room Temperature Sheet Resistance and Absorbtion Coefficient $k$ Deteremined by Ellipsometry at $1300 \mathrm{~nm}$ of Films Grown with an Evaporation Temperature of $130^{\circ} \mathrm{C}(b$.$) .$
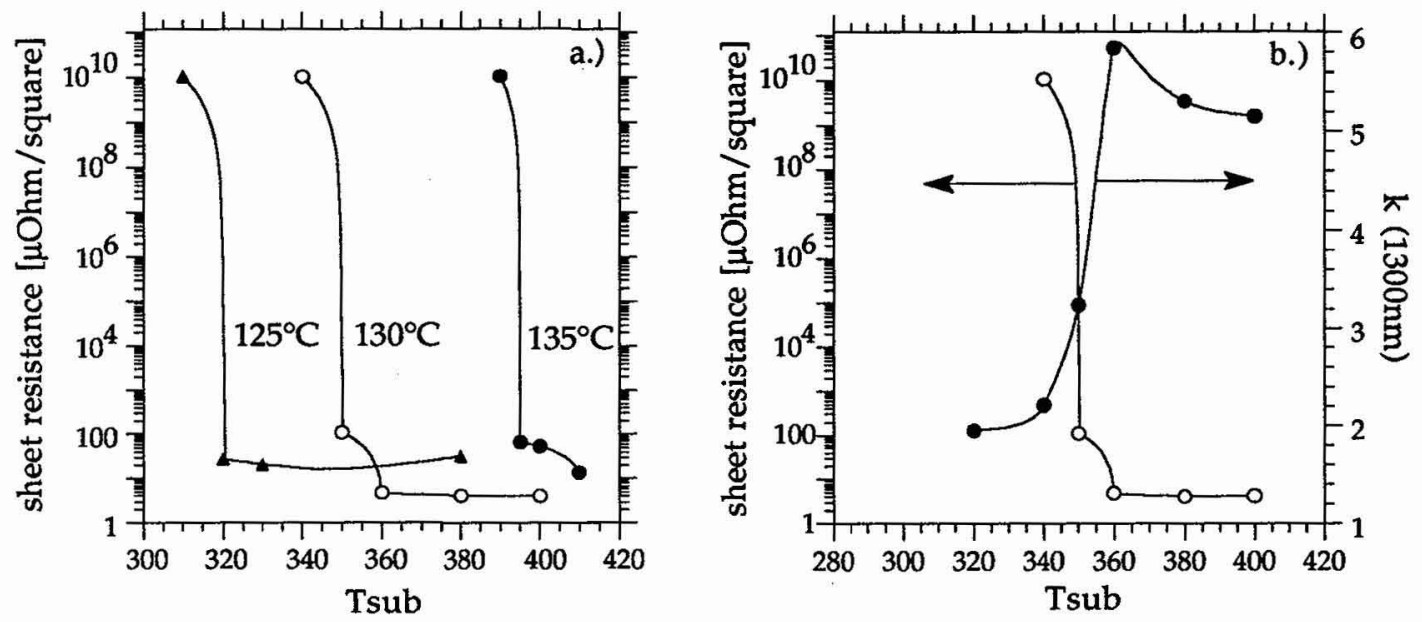

Figure 6: Sheet Resistances Depending on the Substrate Temperature for Hydrogen and Hydrogen/Ethanol as Reaction Gases (HR).

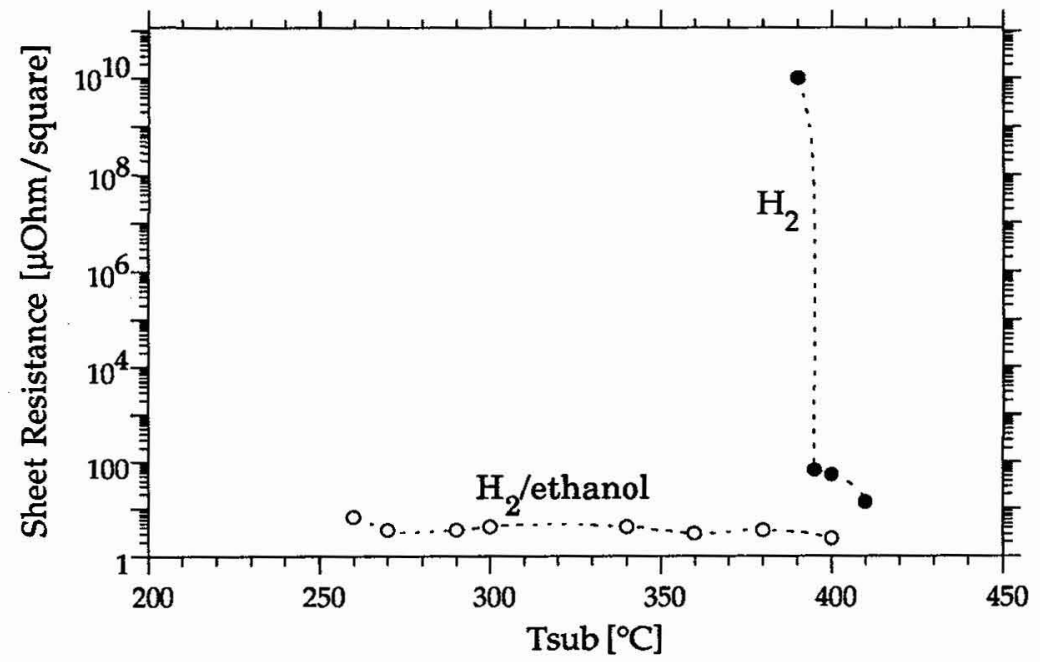

copper films with a low sheet resistance of $3.6 \mu \Omega / \square$ at substrate temperatures of only $270^{\circ} \mathrm{C}$. 
All results can be explained by following scheme:

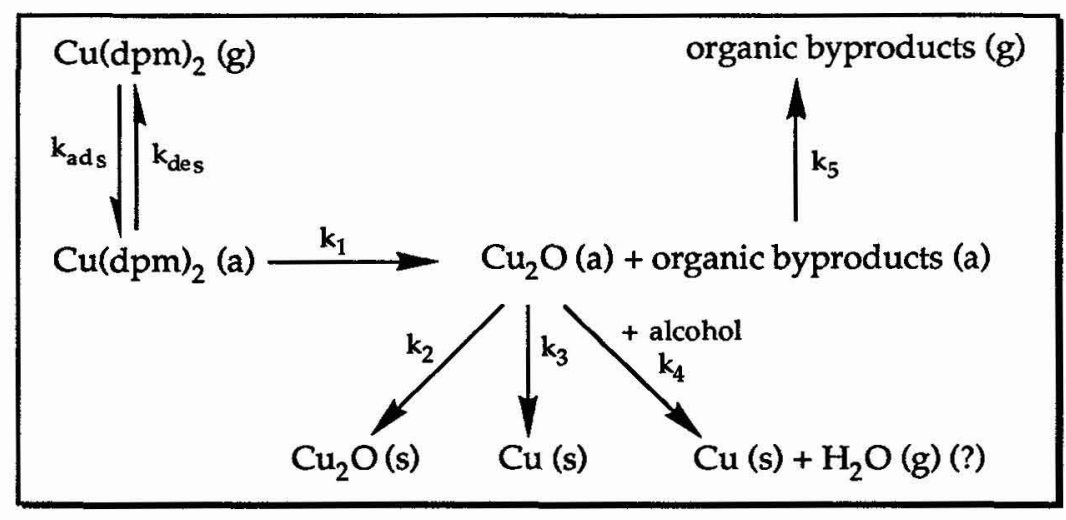

The growth rate is determined by $k_{a d s}$ and $k_{d e s}$ via a Langmuir isotherm. Reaction (1) and (5) are probably very fast and thus they have no influence on the observed kinetics. The reduction of copper(I) to copper(0) can proceed thermally or by reaction with $\mathrm{H}_{2}$ or alcohols. At low substrate temperatures (growth of oxide films) the reaction rate $\mathrm{k}_{3}$ is to small for complete reduction of $\mathrm{Cu}_{2} \mathrm{O}$ and a mixture of this oxide and copper is formed. At high substrate temperatures $\mathrm{k}_{3}$ increased significantly because of its exponential dependence on the temperature and now the reaction is fast enough for almost $100 \%$ conversion into copper(0). Ethanol opens a new pathway to copper via reaction (4) which seems to be quite fast even at very low temperatures of $270^{\circ} \mathrm{C}$. More investigations are in progress in both MOCVD systems to verify this mechanism.

\section{Conclusions}

It was shown that the growth kinetics of copper and copper oxide films depend on the MOCVD system (horizontal or vertical), on the substrate temperature and on the reaction gas. The dependence of the growth rate on the partial pressure of the precursor is surface limited with a Langmuir isotherm for the horizontal MOCVD system and mass flow controlled for the vertical system. When the experiments were performed under hydrogen, a sharp transition from non-conductive to metallic was seen at temperatures that were dependent on the evaporation rate or the growth rate, respectively. Ethanol as an additive to hydrogen improved the electrical properties of the films significantly and allowed growth of metallic copper films at $270^{\circ} \mathrm{C}$. A reaction mechanism is given to explain the results.

\section{Acknowledgement}

The research was supported by Kredite für Unterricht und Forschung, ETH Zürich and the Swiss National Research Foundation. 


\section{Literature}

[1] J. Li, Y. Shacham-Diamand and J. W. Mayer, Mater. Sci. Rep. 9 (1992) 1.

[2] L. H. Dubois and B. R. Zegarski, J. Electrochem. Soc. 139 (1992) 3295.

[3] R. Sekine and M. Kawai, Appl. Phys. Lett. 56 (1990) 1466.

[4] R. Sekine, M. Kawai, T. Hikita and T. Hanada, Surf. Sci. 242 (1991) 508.

[5] T. Hikita, R. Sekine, T. Hanada and M. Kawai, Surf. Sci. Lett. 262 (1992) L139.

[6] W. S. Rees and C. R. Caballero, Adv. Mater. Opt. Elect. 1 (1992) 59.

[7] M. Becht, T. Gerfin and K.-H. Dahmen, Chem. Mater. 5 (1993) 137.

[8] G. C. Bond, Catalysis by Metals , 1962, Academic Press, London

[9] F. L. McCrackin, E. Passaglia, R. R. Stromberg and H. L. Steinberg, J. Res. Natl. Bur. Stand. 67A (1963) 363.

[10] P. M. Jeffries, L. H. Dubois and G. S. Girolami, Chem. Mater. 4 (1992) 1169.

[11] B. Lecohier, B. Calpini, J.-M. Phillipoz, T. Stumm and H. vandenBergh, Appl. Phys. Lett. 60 (1992) 3114.

[12] C. C. Cho, Tungsten and Other Advanced Materials for VLSI/ULSI-VI (1990) 189. 